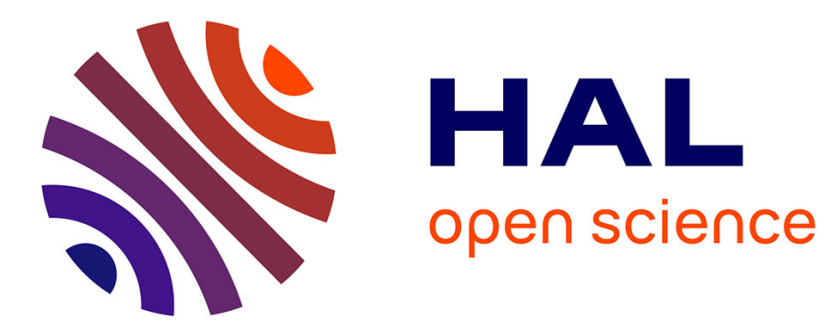

\title{
Role and Characterization of Surfaces in the Aluminium Industry
}

\author{
H. Dunlop, M. Benmalek
}

\section{To cite this version:}

H. Dunlop, M. Benmalek. Role and Characterization of Surfaces in the Aluminium Industry. Journal de Physique IV Proceedings, 1997, 07 (C6), pp.C6-163-C6-174. 10.1051/jp4:1997614 . jpa-00255713

\section{HAL Id: jpa-00255713 https://hal.science/jpa-00255713}

Submitted on 1 Jan 1997

HAL is a multi-disciplinary open access archive for the deposit and dissemination of scientific research documents, whether they are published or not. The documents may come from teaching and research institutions in France or abroad, or from public or private research centers.
L'archive ouverte pluridisciplinaire HAL, est destinée au dépôt et à la diffusion de documents scientifiques de niveau recherche, publiés ou non, émanant des établissements d'enseignement et de recherche français ou étrangers, des laboratoires publics ou privés. 


\title{
Role and Characterization of Surfaces in the Aluminium Industry
}

\author{
H.M. Dunlop and M. Benmalek \\ Pechiney, Centre de Recherches de Voreppe, BP. 27, 38340 Voreppe, France
}

\begin{abstract}
Aluminium is used extensively in the transportation, architecture, electronic and packaging industries. Aluminium presents particular characteristics such as low density, high ductility and a highly protective natural oxide film. However, formability, corrosion resistance, weldability, adhesion and surface aspect depend on the chemistry and microstructure of the metal surface. Properties of particular importance include the oxidation state, the degree of hydration and surface modifications induced by transformation and storage. For surface finishing processes it is necessary to determine the nature of chemical species created and their interactions with the substrate. Modern methods of surface characterization are extensively applied to solve these issues. Techniques such as X - ray photoelectron spectroscopy (XPS), Auger microscopy, secondary ion mass spectrometry (SIMS) and electron microscopy (TEM and SEM) are used routinely. In addition novel approaches are starting to be used systematically for industrial research (X - ray absorption spectroscopies, time of flight static SIMS and atomic force microscopy) after an initial phase of development in university laboratories. The use of these methods combined with studies of adsorption of model compounds leads to a better understanding of interfacial phenomena. For surface analysis to successfully contribute to R\&D programmes, the representativity and data quantitation have to be assured. Use of several, complementary, methods enables interpretations to be confirmed. The principal applications of aluminium involving a high degree of surface technology are reviewed together with recent examples of the use of the aforementioned methods, in particular concerning the optimization of aluminium surfaces before subsequent surface finishing.
\end{abstract}

\section{INTRODUCTION}

Aluminium and aluminium alloys are used extensively for a wide range of applications in the aerospace, automotive, architectural, electronic and packaging industries. The versatility of aluminium in these fields is due in part to its specific properties such as low density, high ductility, good oxygen barrier properties, high thermal and electrical conductivities, high reflectivity over a wide spectral range and high mechanical strength when alloyed. Other benefits include the low working cost and high scrap value of aluminium. However, the one particular property to which the aluminium industry owes its existence is the highly protective nature of the thin but tenacious $\mathrm{Al}_{2} \mathrm{O}_{3}$ oxide film ubiquitously present on aluminium and which remains stable over a wide range of $\mathrm{pH}$ from 3 to 9 . The oxide is also an excellent substrate for receiving a variety of surface treatments which are often applied to aluminium to further improve corrosion resistance in aggressive environments or to promote durable adhesion with polymeric materials [1].

The performance of the metal during production processes, surface finishing and subsequent service life is nevertheless highly dependent on being able to optimise the composition, chemistry, thickness and the microstructure of the surface oxide formed at each stage. In this context modern methods of surface and near surface characterization are now extensively applied. The most commonly used are often to be found in-house in industrial aluminium research centres: Infra-red spectroscopy (IR); electrochemical impedance spectroscopy, optical ellipsometry, surface energy and wettability measurements, X-ray photoelectron spectroscopy (XPS or ESCA); Auger microscopy (AES); Secondary ion mass spectrometry (SIMS); and scanning or transmission electron microscopy (SEM, TEM). When considered together they cover the range of detection limits, chemical specificity, lateral and depth resolutions required, although no one 
technique can cover all aspects satisfactorily. In addition, certain novel methods such as atomic force microscopy (AFM) [2], X-ray absorption near edge structure (XANES) using synchrotron radiation [3], and time of flight static SIMS [4] are starting to be used systematically after an inital development phase in public laboratories. This is because they offer very high lateral resolution, improved chemical environment and local order determinations, and surface molecular information. A requirement for successful surface analysis in industrial R\&D is to be able to assure the representativity and quantitation of the results and by applying several complementary techniques be able to confirm data interpretations. The successful application of these methods also depends on prior information acquired by bulk metal analysis.

The aim of this paper is to illustrate the role and characterization of surfaces in the aluminium transformation industry based on experience gained in an industrial R\&D department operating in areas of development of new products and processes; improvement of existing products; and plant problem solving. Considered here are products essentially issued from wrought aluminium such as rolled metal sheet and foil; aspects related to surfaces on cast products or on liquid metal are outwith the scope of this paper. The areas we address below cover two principal domains: an overview of the wide range of products requiring surface expertise; and more detailed examples concerning the examination of the chemical state and microstructure of aluminium surfaces before subsequent surface finishing.

\section{ALUMINIUM APPLICATIONS AND SURFACE TREATMENTS}

Wrought aluminium thin sheet and foil are the basis for a wide range of products including 2 piece drawn and ironed beverage cans, aerosols, electrolytic capacitors, reflectors, household food foil and flexible, multilayered packaging products such as yoghurt pot lids, cheese wrap, coffee packs, fruit juice cartons, toothpaste tubes. Thicker products include alloy sheet for car body panels and for heat exchanger tubing. Hardened aluminium alloys are the principal materials used in aircraft construction. Because mechanical requirements vary enormously according to the application, a large range of alloys are used including high purity $4 \mathrm{~N}$ grade (e.g.: electrolytic capacitors), technical purity 1000 series, $99.5 \%$ purity (thin foil packaging applications), $3000 \mathrm{Al}-\mathrm{Mn}-\mathrm{Si}$ series (can bodies), $5000 \mathrm{Al}-\mathrm{Mg}$ series (can ends and automobile inner body parts), $6000 \mathrm{Al}-\mathrm{Mg}-\mathrm{Si}$ series (automobile exterior skins) and the $2000 \mathrm{Al}-\mathrm{Cu}$ and $7000 \mathrm{Al}-\mathrm{Zn}$ series (aeronautic applications). For each application specific surface finishing treatments have been developed through extensive research. They allow improved corrosion resistance in various environments and for different alloys, the promotion of durable adhesive bonds with polymer films, lacquers and paints or the optimization of specific surface properties such as reflectivity. They thus act as a more homogeneous and stable interface to external coatings or the ambient atmosphere than the original oxide. Surface treatments sensu stricto fall into two major categories: chemical (degreasing, conversion . . .); and electrochemical (anodization, etching ....). Further surface finishing by application of coatings include lacquers, PVD and CVD coatings, laminated or extruded polymer films and porcelain enameling.

Sheet and foil are often lacquered directly after degreasing performed by annealing (thin foil) or after additional chemical acid or alkaline solution cleaning (beverage can bodies). In this case where no further surface finishing is employed, surface hydration, segregation and contamination are especially critical and have to be optimised to insure adequate bonding with the lacquer. These aspects are considered in more detail in section 3 .

Etching and brightening are used for capacitors, jewellery and for optical applications. The principal function of AC or DC etching is to increase the surface area of a foil for use as an electrolytic capacitor electrode $[5,6]$. Electrolytic or chemical brightening processes are operated on Al foils when the surface aspect is an issue, i.e. for decorative or optical applications. Etching and brightening are more effective on high purity alloys, where the chemical attack of the surface is very uniform and no grain boundary dissolution occurs. The treated surface develops a thin and regular oxide layer $(2-20 \mathrm{~nm})$ where the chemical structure varies from anhydrous oxide to hydroxides (boehmite, ...). In most cases, the developed oxide serves as a base film to other processes: anodizing after etching or a PVD coating after brightening.

Anodizing is widely used in the aluminium industry [7]. Broadly speaking anodization is any treatment where aluminium is immerged as the anode in an aqueous electrolyte and subject to a potential. This results in oxide coatings which can vary widely in thickness, colour, hardness, aspect and electrical properties depending essentially on the composition of the bath and the voltage [1]. The majority of anodic processes give rise to porous films and are based on chromic acid, sulfuric acid or phosphoric acid electrolytes. Sulfuric acid anodization (SAA) is the most widely used, for decoration and protection 
purposes, with film thickness ranging from 2 to $100 \mu \mathrm{m}$. Chromic acid anodization (CAA) is mainly used in the aeronautic industry as a basis for structural adhesives and for its hydration inhibiting properties. Phosphoric acid anodization (PAA) gives rise to a highly porous and fibrous film. It has found applications in the aeronautic industry and thin PAA films are employed when good adhesion is required with polymers or porcelain enameling. PAA treatments retard hydration and slow the rate of transformation of the oxide to hydroxides [8] through the creation of insoluble phosphate species in the outer atomic layers. Another major anodization variant is barrier anodization. It is done under near neutral $\mathrm{pH}$ where the oxide is not dissolved and gives rise to a compact and insulating barrier film on high purity metal used for electrolytic capacitors.

To achieve good corrosion and weight reduction; aluminium alloys are employed for can bodies and automobile parts [9]. However, these applications need specific surface treatments in order to improve adhesiveness to lacquers or paints. Finishing industries have developed processes to induce thin layers of modified oxide. The thickness and the structure of such layers have to be controlled as they determine surface coverage and mechanical properties. Conversion coatings containing chromium are among the most widely used interlayers; their structures and compositions have been described in the literature $[10,11]$. Surface investigations based on novel techniques can help to increase our knowledge and thus to improve the processes. In chromate conversion coatings, the corrosion protection is said to be due to the corrosion inhibiting effect of chromium VI and to the physical barrier related to the film thickness. In chromium phosphate conversion coatings, corrosion resistance is improved because phosphate ions retard hydration as in PAA coatings. Due to environmental pressure, chromium free processes containing active species based on $\mathrm{Ti}$ or $\mathrm{Zr}$ are currently under development $[12,13]$. However the corrosion protection of these new layers does not reach the same level as with chromates. An improved understanding of the comparative role between $\mathrm{Cr}, \mathrm{Ti}$, and $\mathrm{Zr}$ ions or complexes is needed to clarify the behaviour.

Zinc phosphating is widely used in automotive applications. This treatment demonstrates a good aptitude for corrosion protection and to paint bonding on steel. It has been retained as a surface preparation of aluminium alloys for automobile body parts $[14,15]$. Adapted, fluoride containing, treatment baths are in use in order to allow the treatment of Al and steel with the same surface treatment lines. Investigations showed that fluorine is active in the dissolution of the surface oxide and in complexing dissolved aluminium ions.

Modification of aluminium alloy surfaces by means of vacuum deposited coatings is now finding widescale applications. For example multilayer coatings have been developed for the protection of aluminium surfaces and to improve optical properties [16]. The coatings are made of transparent oxides such as $\mathrm{SiO}_{2}$ and $\mathrm{TiO}_{2}$ which exibit adequate refractive indexes and good protective properties. To ensure optimal properties, chemical composition and precise thicknesses have to be found. Reflectivity enhancement can be obained using a stack of quarter-wave layers of low refractive index $\left(\mathrm{SiO}_{2}\right)$ and high index $\left(\mathrm{TiO}_{2}\right)$ materials. The structure allows an augmentation of $>5 \%$ of the initial reflectance of Al. Using PVD techniques, high levels of adherence are obtained provided that an ionic etching precedes the deposition .

\section{NATURE OF SUPERFICIAL OXIDES FORMED ON WROUGHT ALUMINIUM}

A thin (2-4 nm) and protective glassy oxide film forms instantaneously on aluminium on contact with air. This is due to the highly electronegative character of the metal and its strong affinity for oxygen as evidenced by the heat of formation of $\mathrm{Al}_{2} \mathrm{O}_{3}$. Amorphous, spinel type, transition aluminas are amphoteric and their marked overall basic polarity [17] enables the formation of chemical bonds with polymer coatings. The high molecular volume of the oxide film means that it is under compressive stress and can undergo a certain amount of substrate deformation without rupturing. However, fine scale modifications of the chemistry and the structure of oxides formed on aluminium sheet and foil (figure 1) after cold working, heat treatments, and inevitable metal storage have to be determined at each stage and optimized. They govern the efficiency of further metal forming operations (drawing, welding) and subsequent application of lacquers, polymer films or other surface treatments. Aluminium sheet and foil are often heat treated (annealed) in order to modify metallurgical properties and to remove rolling lubricant residues by thermal degreasing. The annealing conditions ( $T, t$, atmosphere) have to be optimized for efficient lubricant removal and at the same time to minimize hydration and tramp or alloying element surface segregation (essentially $\mathrm{Mg}$ ) which can all be possible origins of polymer adhesion loss [18-20]. During subsequent metal 
operations, for example drawing, ironing, extrusion or stamping, metal behaviour can change drastically as a function of oxide thickness, crystallinity or chemical composition from running smoothly to producing a range of surface defects resulting from galling occuring between the metal and the forming tool [21].

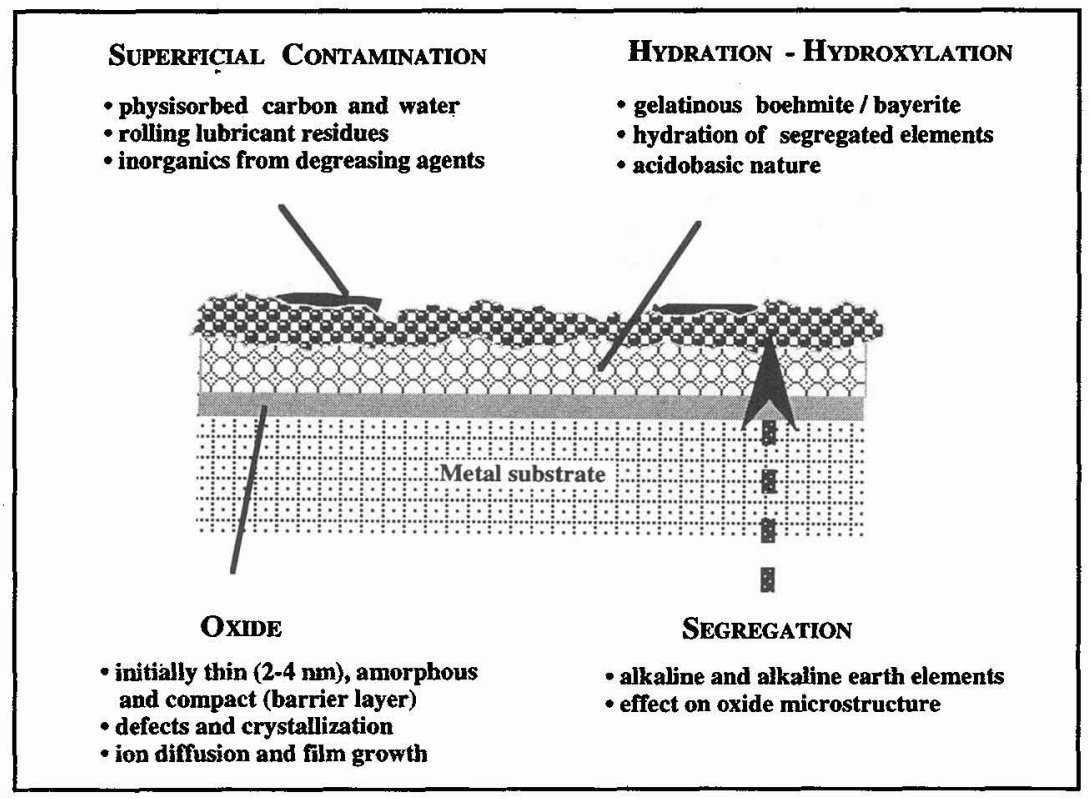

Figure 1: Overview of aluminium surface phenomena

\subsection{Characterization and properties of industrial aluminium surfaces}

In all the areas described above surface techniques are employed extensively to improve the understanding of surface phenomena. In the areas of contamination surface FTIR [20, 22-24], XPS [25], static, quadrupole or ToF SIMS [26, 27] combined with the study of in-situ interactions between representative model molecules and substrates have proved pertinent in determining the surface concentrations and molecular chemistry of lubricant residues and their interactions with aluminium surfaces. Adhesion loss is clearly correlated with increasing surface residues [20] and heat treatments can give rise to chemical reactions with rolling oil fatty acid additives leading to the formation of $\mathrm{Al}$ and $\mathrm{Mg}$ carboxylate soaps [22, $23,25,26,28,29]$. This results in the blocking of polar basic sites on the aluminium oxide surface which are normally the key sites for polymer adhesion. With this information in hand rolling oil compositions can be optimised to minimize the phenomenon. Recent novel approaches appear to be efficient in eliminating organic residues, stabilizing the aluminium oxide and can increase the number of basic sites available for polymer adhesion. They consist of physically treating the surface with oxygen plasmas [30, 31], with corona discharge [32] treatments or by $\mathrm{CO}_{2}$ laser bombardment [33]. Another possible alternative lies in the development of epoxy adhesives polymerized with amidoamine curing agents capable of bonding directly to oily substrates without prior degreasing $[34,35]$.

The formation of hydrated alumina during annealing can fause excess "stickiness" between metal surfaces giving rise to tearing when the coil is unwound [36]. Lacquer adhesion loss can be attributed to varying degrees of hydration and hydroxylation occuring during heat treatments and after storage in humid conditions $[19,37,38]$. The amorphous oxide initially physisorbs water (reversible), which may then become capped with poorly crystallized gelatinous pseudoboehmite, AlOOH. $\mathrm{xH}_{2} \mathrm{O}$ where water molecules are intercalated between octahedral layers of the boehmite structure. Extended, irreversible hydroxylation, 
resulting from dissolution and reprecipitation, gives rise to the formation of friable bayerite, $\mathrm{Al}(\mathrm{OH})_{3}$, microcrystallites (figure 2). Aluminium hydroxides can be considered as being basic and as such favorable for interaction with acid polar sites on polymers. However hydration as opposed to hydroxylation may reduce overall adhesion performance because in this case the sites are linked by relatively weak bonds. In the case of hydroxylation decohesion can result within the oxide layer. Oxidation and hydration can also be accelerated in the presence of alkaline and alkaline earth elements $(\mathrm{Li}, \mathrm{Na}, \mathrm{Mg}$ ) segregated at the surface or at the metal - oxide interface $[18,39,40] . \mathrm{Mg}$ in particular migrates at elevated temperatures during heat treatments depending on the initial bulk concentration and alloy grain size [41]. Surfaces are more prone to lacquer adhesion loss in the presence of $\mathrm{Mg}$ because, although its oxide is basic and can have reasonable initial bonding with the lacquer acid sites, unlike $\mathrm{Al}_{2} \mathrm{O}_{3}$ it dissolves easily in neutral humid environments where the protection offered by polymer coatings is limited due to a certain degree of permeability [41]. The corrosion resistance of $\mathrm{Mg}$ rich oxides is notably improved if $\mathrm{MgCO}_{3}$ formation is promoted instead of more soluble $\mathrm{Mg}(\mathrm{OH})_{2}[42,43]$. Similar species have been shown to occur on $\mathrm{Mg}$ alloys by XPS [44].

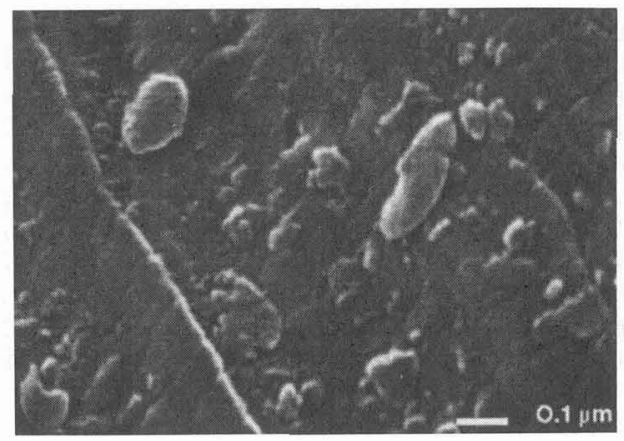

Figure 2: Secondary electron image (STEM) showing surface morphology of hydroxylated aluminium.

The initially amorphous oxide may become progressively thicker, more ordered and may eventually crystallize as $\gamma-\mathrm{Al}_{2} \mathrm{O}_{3}$ during heating at temperatures $>400^{\circ} \mathrm{C}$ [45-47]. This can result in loss of cohesion of the oxide with the metal substrate [48] due to creation of stresses within the oxide film. Crystallization can also accelerate further oxide growth giving rise to loss of oxide film continuity and formation of short circuit diffusion paths for oxygen [49]. Crystalline oxide growth is also promoted in the presence of $\mathbf{M g}$ which can act as a nucleant for $\gamma-\mathrm{Al}_{2} \mathrm{O}_{3}$ crystallization [50]. Depending on heat treatment conditions and $\mathrm{Mg}$ content $\mathrm{MgO}, \mathrm{Al}_{2} \mathrm{MgO}_{4}$ or $\mathrm{Mg}$ doped $\mathrm{Al}_{2} \mathrm{O}_{3}$ [51] form at the surface or within the oxide layer. $\mathrm{MgO}$ microcrystallites can also form as a result of secondary reduction of $\mathrm{Al}_{2} \mathrm{O}_{3}$ by $\mathrm{Mg}$. Hence more complex $\mathrm{Al}-\mathrm{Mg}$ mixed oxides tend to form on $\mathrm{Mg}$ rich alloys [52]. They can be controlled, for example, on 5182 alloy sheet for automobile applications, through study of the degree of surface $\mathrm{Mg}$ coverage with the $\mathrm{Mg} /(\mathrm{Mg}+\mathrm{Al})$ XPS ratio [35].

\subsection{Recent developments in surface analysis applied to aluminium surfaces}

A good picture of the above phenomena is thus usually obtained by combinations of several surface analytical methods. TEM combined with ultramicrotomy or after dissolution of the metal substrate permits detailed morphological and microstructural studies [53, 54]. Variations in composition as a function of depth, applicable to quantification of surface segregation for example, are usually effected by means of SIMS, AES or XPS depth profiles and SIMS imaging $[18,55]$. Surface compositions and chemistry are determined by XPS, grazing incidence IR and static SIMS. In order to better predict and optimize adhesion behaviour other ways are currently being explored for characterizing the degree of hydration, molecular 
structure and the acid - base character of aluminium surfaces. These include XPS, ToF-SIMS, XANES, AFM and photoelectrochemistry, some of which are considered below.

\subsubsection{XPS}

XPS is particularily versatile, fast and powerful for aluminium surface characterization. In addition to providing panoramic surface analysis of all elements from $\mathrm{Li}-\mathrm{U}$, certain information concerning chemical species and states and stoichiometries can be obtained. HO-Al bonds can be distinguished from $\mathrm{O}-\mathrm{Al}$ on the XPS O1s spectrum, based on data from pure bulk standards of alumina $\left(\mathrm{Al}_{2} \mathrm{O}_{3}\right)$, boehmite and diaspore $(\mathrm{AlOOH})$ and gibbsite $\left(\mathrm{Al}(\mathrm{OH})_{3}\right)[4,56]$. Oxide film growth kinetics as function of $\mathrm{T}, \mathrm{t}$ and atmosphere may be followed by determination of the $\mathrm{Al}^{3+} / \mathrm{Al}^{\circ}$ ratio from the $\mathrm{Al} 2 \mathrm{p}$ spectrum $[57,58]$. The $\mathrm{Al} 2 \mathrm{p}$ metal oxide energy separation has also been proposed as an indicator of the degree of local ordering or crystallinity [46] but it appears more likely to be a result of charging effects [59] where charging, determined relative to the position of the adventitious carbon $\mathrm{C} 1 \mathrm{~s}$ peak, appears positively correlated with oxide thickness [3]. This charge - thickness relationship can be used to calculate the oxide charge carrier density within a family of similar materials.

Acid-base properties of bulk materials have been widely exploited, especially in the field of catalysis, where many methods are available such as PZC (point of zero charge), FTIR, solvatochromism etc [reviewed in 17]. Consideration of acid-base properties also contributes to the understanding and optimization of adhesion between materials. Unfortunately the aforementioned methods are not always very appropriate for surface characterization of thin passive films on metallic substrates. A novel application of XPS has been developed recently for the study of acid-base properties of variously treated Al surfaces [60-65].The basis for this method is the measurement of Fermi energy (defined as the difference between the Fermi level and the top of the valence band) from linear correlations between suitably charge referenced Al $2 p$ (oxide) and $O$ is (oxide) peak energies. The degree of surface basicity in the Lewis sense decreases with increasing Fermi energy. In this way we have been able to classify the basicity of various aluminium surfaces: boehmite layer $>$ thermal oxide $>\mathrm{NaOH}$ degreased cold rolled surface $>$ as cold rolled [3].

Nevertheless XPS, when taken alone, is traditionally somewhat limited for the study of more subtle variations in aluminium oxide and hydroxide surface stoichiometry. For example, FTIR analysis [66] suggests that the presence of at least 3 hydroxyl species is possible on $\gamma-\mathrm{Al}_{2} \mathrm{O}_{3}$ attributed to bound water, and variably basic $\mathrm{OH}$ groups. XPS is habitually restricted to determining $\mathrm{OH} / \mathrm{O}-\mathrm{Al}$ ratios semiquantitatively but improved peak analysis in conjunction with results obtained by other techniques (IR, ToF-SIMS) may permit more detailed investigations of hydration and hydroxylation. XPS O 1s peak analysis becomes complicated when dealing with mixed Al-Mg oxides where peaks of many species (carbonates, hydroxides, oxides) are present in the O 1s envelope. XPS valence band spectra have also been exploited successfully with $\mathrm{X} \alpha$ calculations for the study of aluminium hydroxides and oxides [67] but, due to the depth of analysis $(>7.5 \mathrm{~nm})$ and limited resolution, cannot distinguish satisfactorily between hydroxides and oxyhydroxides.

\subsubsection{ToF-SIMS}

Time of Flight Secondary Ion Mass Spectrometry appears to offer a technique capable of supplying detailed chemical and molecular information of surfaces. The method consists of bombarding the sample with a pulsed primary ion beam with a dose $<1.10^{13}$ atoms $/ \mathrm{cm}^{2}$. This low dose minimizes surface damage and erosion permitting "static" analysis of molecular ions emitted from the uppermost $1.5 \mathrm{~nm}$. Time of flight mass spectrometry has the advantages of parallel data acquisition, high mass resolution and unlimited mass range. Insulators can be analysed through the simultaneous use of a pulsed beam of low energy electrons to compensate for charging. Its other advantages are very good detection limits $(<10 \mathrm{ppm})$ and high lateral resolution $(0.2 \mu \mathrm{m})$. Although the presence of direct structural fragments in the SSIMS spectra in covalently bound systems such as polymers is beyond question [68], the presence of such species in spectra from ionic solids is less clear cut. Theoretical studies $[69,70]$ have suggested that for larger clusters at least, the spectrum should be dominated by fragments formed in the near surface region by species which although 
spatially related, are not immediate lattice neighbours. Nevertheless experimentalists claim detailed chemical and structural information is observed in such SSIMS spectra. Indeed Reed and Vickerman [71] suggest that "the relationship between the static SIMS spectrum and chemical structure is well illustrated by the metal oxides".

ToF-SIMS has recently been used $[4,72]$ to characterize oxide/hydroxide films on aluminium metal foils. Samples examined included as cold rolled, annealed and hydroxylated under conditions optimised to form either pseudoboehmite or bayerite. Reference spectra were obtained from alpha and gamma $\mathrm{Al}_{2} \mathrm{O}_{3}$, boehmite $\mathrm{AlOOH}$, hydrated diaspore $\mathrm{AlOOH}$, and gibbsite $\mathrm{Al}(\mathrm{OH})_{3}$ bulk powders. The SIMS fragments observed were then correlated with known surface chemistry based on other methods, in particular XPS. A rich SIMS spectrum in $\mathrm{Al}_{\mathrm{x}} \mathrm{O}_{\mathrm{y}}(\mathrm{OH})_{\mathrm{z}}$ clusters was observed, frequently extending to more than 1000 Daltons (figure 3a). High mass resolution enabled unambiguous attributions to be made. For example it is possible to distinguish between $\mathrm{Al}_{5} \mathrm{O}_{7}(\mathrm{OH})_{2}$ at 280.878 a.m.u. and $\mathrm{C}_{18} \mathrm{H}_{33} \mathrm{O}_{2}$ at 281.248 a.m.u. The clusters are invariably those with a calculated net charge of +1 in positive secondary ion spectra and - 1 in negative spectra (based on formal charges). On the basis of stoichiometry and abundance the systematics of the fragments were determined. Thus for $\mathrm{x}=2$, the series of fragments $\mathrm{Al}_{2} \mathrm{O}_{3}(\mathrm{OH}), \mathrm{Al}_{2} \mathrm{O}_{2}(\mathrm{OH})_{3}, \mathrm{Al}_{2} \mathrm{O}(\mathrm{OH})_{5}$, and $\mathrm{Al}_{2}(\mathrm{OH})_{7}$ was observed. Given that similar fragments were observed from all the samples, either the external surfaces are essentially the same or stoichiometric and structural information is contained in differences across and within families of peaks. The former argument is countered by XPS evidence (although a greater depth is analysed) where the $\mathrm{Al}: \mathrm{O}$ ratio and deconvolution of the $\mathrm{O} 1 \mathrm{~s}$ peak yields close to anticipated stoichiometries and chemical shifts. There is good agreement between the anticipated and the detected surface structures where the metal surface, treated under conditions in which bayerite (trihydroxide) should dominate, lies very close to gibbsite, as does the cold worked surface (figure $3 b$ ). Annealing treatment causes dehydroxylation, moving the data towards that of alumina. The surface treated to optimise pseudoboehmite formation lies close to the gamma alumina data, suggesting the surface may be a partially hydroxylated oxide rather than a true oxide hydroxide. The authors concluded that for these specimens the surface structure plays a limited role in defining the fragments formed, although it must influence the overall abundance of fragments. The method clearly has considerable potential in characterizing the degree of hydration - hydroxylation of these surfaces.
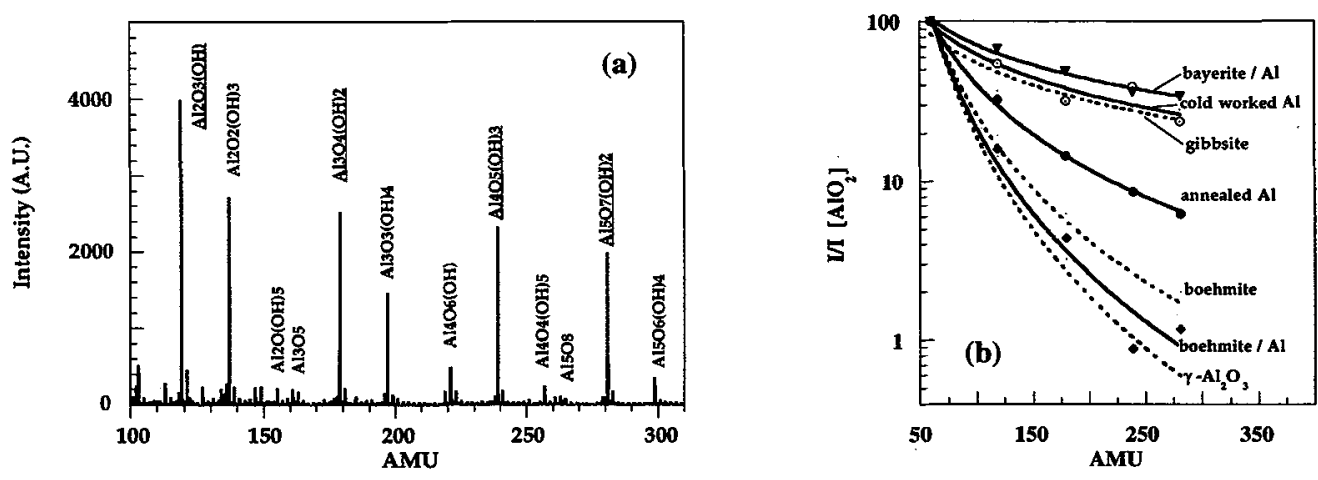

Figure 3: (a) Negative ToF-SIMS spectrum of gibbsite showing series of $\mathrm{Al}_{x} \mathrm{O}_{y}(\mathrm{OH})_{z}$ fragments; (b) variations in relative intensities of the most intense member of each series (underlined in 3a) fitted to power law curves, for reference oxide and hydroxide powders (dotted lines) and treated metal surfaces (full lines; triangles: bayerite on Al; open circles cold worked Al; full circles: annealed $\mathrm{Al}$; diamonds: boehmite on $\mathrm{Al}$ ) $[4,72]$.

\subsubsection{X-ray absorption near edge structure (XANES)}

XANES (sometimes called NEXAFS, Near Edge X-ray Absorption Fine Structure) is based on the photoexcitation of electrons from a core level (e.g. K shells of aluminium, carbon and nitrogen) [73] to empty 
states by irradiation with tunable, monochromatised and polarized synchrotron X-rays. $\pi^{*}$ resonances may occur from the excitation toward unoccupied $\pi^{*}$ orbitals in the material; the energy required is less than the ionization potential due to Coulomb interaction between the photoelectron and the created core hole. $\sigma$ shape (or $\sigma^{*}$ ) resonances appear for higher excitation energies due to back and forth scattering of the photoelectrons along the internuclear axis between the absorbing atom and its neighbours: information about interatomic distances may be drawn from this type of resonance. XANES provides key information about the local ordering of atoms and can determine certain chemical states with precision and as such is complementary to methods such as XPS or FTIR. For example $\mathrm{Cr}^{\mathrm{VI}}$ can be easily distinguished from $\mathrm{Cr}^{\mathrm{III}}$ in chromate conversion coatings, used in the aeronautic industry as the interface for structural adhesives $[74,75]$. Distinction can also be made without ambiguity between different hybridized bonds in organic materials (e.g. $\mathrm{C}-\mathrm{C}, \mathrm{C}=\mathrm{C}, \mathrm{C} \equiv \mathrm{C}$ bonds) or those resulting from adsorption on metals (metal carboxylates may be differentiated from carboxylic acids).

Electron yield Al K - edge XANES has proved successful for the quantitation of coordination numbers $(\mathrm{CN})$ of aluminium in oxides and aluminosilicates $[76,77]$ and other workers have extended the method to aluminium oxide surfaces [78]. After demonstrating the capability to distinguish between 4, 5 and 6 coordinated aluminium in $\gamma$-alumina (CN: 4 and 6) $\alpha$ - alumina, boehmite and gibbsite (CN: 6$)$ and andalusite (CN: 5 and 6), Robinson et al analysed typical aluminium surfaces by XANES and MAS-NMR and illustrated that as formed barrier and porous anodic oxides have no long range order and exhibit mainly 4 and 5 - fold coordination. The appearance of 6 - fold coordination is considered indicative of hydration and corrosion. The local coordination of aluminium has also been shown to play a key role in the acid-base characteristics of bulk aluminium oxides, hydroxides and aluminosilicates with MAS-NMR [79-81] and theoretical [82] studies. It was suggested [81] that strongly distorted pentacoordinated Al sites could behave as potential Lewis acid centres, as could other types of coordination if sufficiently distorted.

XANES has also contributed significantly in the field of study of bonding in organic molecules [83, 84] because it is a very sensitive probe for determining chemical environments and for characterizing interactions and orientations of monolayers of organic molecules adsorbed on substrates. XANES has recently been employed for the determination of acid - base properties of surfaces on aluminium in conjunction with photoelectrochemical and XPS investigations [3,17]. Model probe molecules (formic acid and pyridine) were adsorbed in-situ and the degree of interaction and monolayer coverage permitted the establishment of the following basicity scale: alkaline detergent degreased (sodium silicates and phosphates) $<\mathrm{NaOH}$ degreased $<$ thermal oxide $<$ boehmite on $\mathrm{Al}<\mathrm{PAA}$ film $<\mathrm{Mg}$ rich oxide on Al-4.5Mg alloy (figure 4). This scale is in close agreement with that determined by XPS (see 3.2.1 above) and photoelectrochemistry. This example is a good illustration of the necessity to cross - validate results obtained by different techniques, particularily when novel approaches are being used.

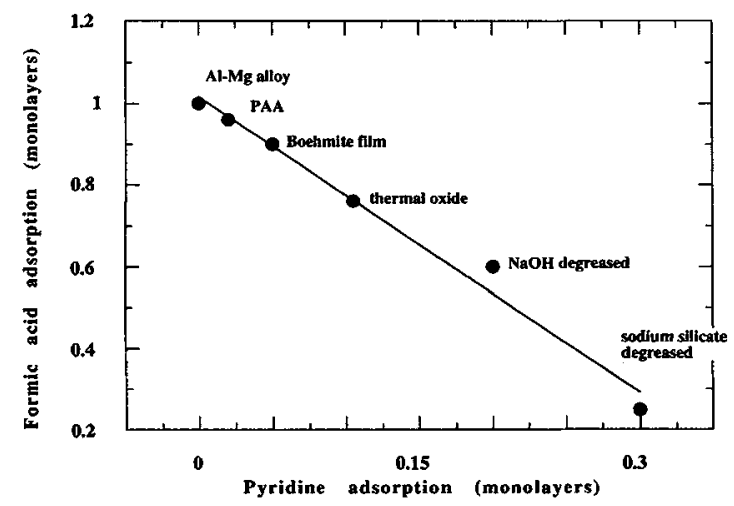

Figure 4: Basicity of aluminium surfaces determined by XANES C K-edge adsorption measurements [17]. 


\section{ANALYTICAL PERSPECTIVES}

New or improved methods will undoubtedly further our understanding of aluminium surfaces in the near future. For example, recent developments in atomic force microscopy, in addition to providing topographic information at the atomic scale, show potential for the nanochemical mapping of local acid-base variations $[86,87]$ and functional groups [88]. Chemical imaging and local atom coordination studies are possible with XANES microscopy with a resolution of better than $50 \mathrm{~nm}$ [89]. Similar information can be obtained on oxides by electron microscopy equipped with electron energy loss spectroscopy (TEM - EELS) [90, 91] where EELS also allows chemical imaging at very high resolution $(<10 \mathrm{~nm})$ [92]. However, EELS is more sample destructive than XANES since the latter depends on X-ray excitation rather than charged particle bombardment. Scanning electron microscopes equipped with field emission electron guns now allow rapid, high resolution morphological studies of surfaces. XPS continues to be developed, with the advent of micron scale imaging photoelectron spectroscopy, either with commercial instruments, or in conjunction with synchrotron light sources. Developments in monochromatic $\mathrm{X}$-ray sources and electron analysers give improved XPS spectral resolution and allow, for example, fine scale vibrational asymmetry effects to be extracted from C 1s spectra of organic materials [85]. Infrared techniques should not be overlooked since they have certain inherent advantages: analysis may be carried out in air; minimal sample preparation is required and its chemical specificity is highly complementary to XPS. In particular there has been renewed interest in IR for surface analysis with the development of grazing incidence spectroscopy [24] and sum frequency generation (SFG-IR) which allow in situ monitoring of surface reaction kinetics [93]. The in situ study of adsorption of model chemical species on aluminium substrates [25, 40, 94-97] with surface techniques remains one of the most efficient ways to study interfacial reactions. This is because it is very difficult to gain access to nanometer thick interfaces in finished products without inducing chemical modifications. Confrontation of experimental data with theoretical $a b$ initio quantum molecular dynamics simulations $[82,98]$ should contribute to the optimization of interfaces in multilayered systems in the future. Evaluation of adhesion quality and strength is another critical area where reliable methods have to be developed. One interesting route is through the determination of shear strength by tensile loading in the SEM [99].

\section{CONCLUSIONS}

The multiple applications of aluminium, the wide range of surface treatments and methods of surface characterization have been reviewed. It was shown that surface properties have to be well characterized at all stages of aluminium transforming processes and finishing treatments. Examples were given from recent published research on the determination of chemical states and microstructure of industrial aluminium surfaces with XPS, ToF-SIMS and XANES. Although a wide range of modern techniques are available, it is necessary to cross-validate results and interpretations through the application of several, complementary and quantitative methods. This is particularly true when using novel approaches which may be unproven for the problem in question.

Some issues requiring deeper knowledge include zinc phosphating, $\mathrm{Ti}$ and $\mathrm{Zr}$ conversion coatings and interfacial phenomena in general. New applications, environmental legislations and production process efficiency are driving forces for research into new ways of aluminium surface finishing. Present trends include the increased use of aluminium for automotive body parts, the reduction or elimination of the use of chromium, PVC and volatile organic compounds and the development of thermoplastic laminates and water based lacquers.

\section{Acknowledgements}

The authors wish to thank their colleagues, thesis students and collaborators, including J. R. Butruille, J. Pannetier, N. A. Thorne, M. Tanaka, S. Lopez, R. Frier, M. Roux - Michollet, D. Terroni, A. Frichet, J. B. Metson, G Tourillon, Tran Minh Duc who have contributed to work cited here. The organisers are gratefully acknowledged for their invitation to participate at this conference. 


\section{References}

[1] Wernick S., Pinner R., and Sheasby P.G., The surface treatment and finishing of aluminium and its alloys. Fifth edition. (Finishing Publications Ltd, Teddington, 1987).

[2] Warner T.J., Schmidt M.P., Sommer F., and Bellot D., Z. Metallkd., 86 (1995) 494-501.

[3] Lopez S., Dunlop H., Tourillon G., Petit J.P., and Butruille J.R., J. Electrochem. Soc. submitted.

[4] Dunlop H.M., Metson J.B., Batier C., Butruille J.-R., and Tran M.D., "Static ToF-SIMS study of cluster ion emission from aluminium oxides and hydroxides". Proc. SIMS X, Münster, Oct 1995, in press.

[5] Jeong J.H., Kim S.S., Kim H.G., Choi C.H., and Lee D.N., Mater. Sci. Forum (Proc. ICAA 5), 217-222 (1996) 1565-1570.

[6] Sato F., Sakurai T., and Hoshino K., Mater. Sci. Forum (Proc. ICAA 5), 217-222 (1996) 16291634.

[7] Lefebvre J., Techniques de l'Ingénieur, M1630 (1990) 1-17.

[8] Metson J.E., Hyland M.M., Gillespie A., and Hemmingsen-Jensen M., Colloids and Surfaces, A93 (1994) 173-180.

[9]. Brown K., J. Metals, (1995) 20-23.

[10] Asami K., Oki M., Thompson G.E., Wood G.C., and Ashworth V., Electrochim. Acta, 32 (1987) 337-343.

[11] Bubert H., Garten R.P.H., Stingeder G., and Wätjen U., Surf. Interface Anal., 12 (1987) 439-441.

[12] Bubert H., Puderbach H., Pulm H., and Roland W.A., Fresenius Z. Anal. Chem., 333 (1989) 304307.

[13] Hinton B.R.W., Metal Fnishing, (1991) 55-61.

[14] Ishii H., Furuyama O., and Tanaka S., Metal Finishing, (1993) 7-10.

[15] Textor M., Néma P., and Timm J., Mat. -wiss. u. Werkstofftech, 26 (1995) 318-326.

[16] Benmalek M., Proc. NATO ARW Protection coatings and thin film synthesis, In press.

[17] Lopez S., Petit J.P., Dunlop H.M., Tourillon G., and Butruille J.R., J.Electrochem.Soc. submitted.

[18] Degrève F. and Lang J.M., in Applied Materials Characterization, W. Katz and P. Williams Eds. (MRS, San Francisco, 1985) pp. 241-262.

[19] Thorne N.A., Thuéry P., Frichet A., Gimenez P., and Sartre A., Surf. Interface Anal., 16 (1990) 236-240.

[20] Treverton J.A. and Thomas M.P., Int. J. Adhesion \& Adhesives, 9 (1989) 211-217.

[21] Lea C. and Ball J., Appl. Surf. Sci., 17 (1984) 344-362.

[22] Ross R.A. and Lemay R., Surf. Technol., 26 (1985) 125-136.

[23] Konstadinidis K., Thakker B., Chakraborty A., Potts L.W., Tannenbaum R., and Tirrell M., Langmuir, 8 (1992) 1307-1317.

[24] Yano F., Burrows V.A., Kozicki M.N., and Ryan J., J. Vac. Sci. Technol., A11 (1993) 219-223.

[25] Underhill R. and Timsit R.S., J. Vac. Sci. Technol., A10 (1992). 2767-2774.

[26] Sondag A.H.M., Raas M.C., and Van Velzen P.N.T., Chem. Phys. Lett., 155 (1989) 503-510.

[27] Treverton J.A., Ball J., and Fairlie M., App. Surf. Sci., 52 (1991) 107-124.

[28] Allara D.L. and Nuzzo R.G., Langmuir, 1 (1985) 52-66.

[29] Allara D.L. and Nuzzo R.G., Langmuir, 1 (1985) 45-52.

[30] Strohmeier B.R., J. Vac. Sci. Technol., A7 (1989) 3238-3245.

[31] Belkind A., Krommenhoek S., Li H., Orban Z., and Jansen F., Surface Coatings Technol., 68/69 (1994) 804-808.

[32] Hansen M.H., Finlayson M.F., Castille M.J., and Goins J.D., Tappi J., 76 (1993) 171-176.

[33] Critchlow G.W., Brewis D.M., Emmony D.C., and Cottam C.A., Intl. J. Adhesion Adhesives, 15 (1995) 233-236.

[34] Hong S.G. and Boeiro F.J., J. Appl. Polymer Sci., 55 (1995) 437-449.

[35] Kucza J.C., Butruille J.R., Hank E., and Lancrenon B., SAE Tech. Rep. Submitted.

[36] Tanaka M. and Botton G.A., "EELS applied to the study of interfcaial products causing adhesion between aluminum foils", Proc. ICEM 13 Paris.Jouffrey B. and Colliex C. Eds. (Les Editions de Physique, Les Ulis, 1994) pp. 667-668.

[37] Alwitt R.S., in Oxides and oxide films 4, J.W. Diggle and A.K. Vijh Eds. (Dekker, New York, 1976) pp. 169-254.

[38] Wefers K. and Misra C., Oxides and hydroxides of aluminum, Alcoa Tech. Rep. 19 (1987) pp 1-92.

[39] Esposto F.J., Zhang C.S., Norton P.R., and Timsit R.S., Surf. Sci., 302 (1994) 109-120. 
[40] Huttel Y., Bourdié E., Soukiassian P., Mangat P.S., and Hurych Z., Appl. Phys. Lett., 62 (1993) 2437-2439.

[41] Textor M. and Amstutz M., Analytica Chimica Acta, 297 (1994) 15-26.

[42] Grauer R. and Textor M., Werkst. Korros., 32 (1981) 340-342.

[43] Kozma L. Olefjord, I., Materials Science and Technology, 3 (1987) 860-874.

[44] Baliga C.B. and Tśakiropoulos P., Mat. Sci. Technol., 9 (1993) 507-511.

[45] Cocke D.L., Johnson E.D., and Merril R.P., Catal. Rev. Sci. Eng., 26 (1984) 163-231.

[46] Jimenéz-Gonzalez A. and Schmeisser D., Surf. Sci., 250 (1991) 59-70.

[47] Rhodin T.N., Frederick B.G., and Apai G., Surf. Sci., 287/288 (1993) 638-643.

[48] Isoyama E., Hasegawa M., and Uchiyama T., Aluminium, 63 (1987) 1151-1156.

[49] Shimizu K., Furneaux R.C., Thompson G.E., Wood G.C., Gotoh A., and Kobayashi K., Oxidation of Metals, 35 (1991) 427-439.

[50] Goldstein B. and Dresner J., Surf. Sci., 71 (1978) 15-26.

[51] Grauer R. and Schmoker P., Werkstoffe und Korrosion, 27 (1976) 769-774.

[52] Field D.J., Scamans G.M., and Butler E.P., Met. Trans., 18A (1987) 463-472.

[53] Thompson G., Mater. Sci. Forum (Proc. ICAA 5), 217-222 (1996) 95-106.

[54] Alwitt R.S., Ortega C., Thorne N.A., and Siejka J., J. Electrochem. Soc., 135 (1988) 2695-2700.

[55] Degrève F., Thorne N.A., and Lang J.M., J. Mater. Sci., 23 (1988) 4181-4208.

[56] Tsuchida T. and Takahashi, H., J. Mater. Res., 9 (1994) 2919-2924.

[57] Gunter P.L.J. and Niemantsverdriet J.W., J. Vac. Sci. Technol., A13 (1995) 1290-1292.

[58] Strohmeier B.R., Surf. Interface Anal., 15 (1990) 51-56.

[59] Barr T.L., Seal S., Chen L.M., and Kao C.C., Thin Solid Films, 353 (1994) 277-284.

[60] Mullins W.M. and Averbach B.L., Surf. Sci., 206 (1988) 29-40.

[61] Mullins W.M. and Averbach B.L., Surf. Sci., 206 (1988) 41-51.

[62] Mullins W.M. and Averbach B.L., Surf. Sci., 206 (1988) 52-60.

[63] Casamassima M., Darque-Ceretti E., Etcheberry A., and Aucouturier M., Appl. Surf. Sci., 52 (1991) 205-213.

[64] Casamassima M., Darque-Ceretti E., Etcheberry A., and Aucouturier M., J. Mater. Sci., 28 (1993) 3997-4002.

[65] Cordier F. and Ollivier E., Surf. Interface Anal., 23 (1995) 601-608.

[66] DeCanio E.C., Bruno J.W., Nero V.P., and Edwards J.C., J. Catal., 140 (1993) 84-102.

[67] Thomas S. and Sherwood P.M.A., Anal. Chem., 64 (1992) 2488-2495.

[68] Benninghoven A., Angew. Chem. Int. Ed. Engl., 33 (1994) 1023-1043.

[69] Winograd N., Harrison D.E., and Garrison B.J., Surf. Sci., 78 (1978) 467-477.

[70] Winograd N., Proc. Solid State Chem., 13 (1981) 285.

[71] Reed N.M. and Vickerman J.C., in Practical Surface Analysis 2, D. Briggs and M.P. Seah Eds.(John Wiley and Sons, Chichester, 1992) pp. 303-366.

[72] Metson J.B. and Dunlop H.M., In Prep.

[73] Tourillon G., Guay D., Fontaine A., Garrett R., and Williams G.P., Faraday Discuss. Chem. Soc., 89 (1990) 275-290.

[74] Kendig M.W., Davenport A.J., and Isaacs H.S., Corrosion Sci., 34 (1993) 41-49.

[75] Lytle F.W., Gregor R.B., Bibbins G.L., Blohowiak K.Y., Smith R.E., and Tuss G.D., Corrosion Sci., 37 (1995) 349-369.

[76] Li D., Bancroft G.M., Fleet M.E., Feng X.H., and Pan Y., Am. Mineral., 80 (1995). 432-440.

[77] McKeown D.A., Phys. Chem. Minerals, 16 (1989) 678-683.

[78] Robinson J., Thompson G.E., and Shimizu K., "Towards a structural model for anodic alumina", Proc. 7th Intl. Symp. Oxide films on metals and alloys. Hebert K.R. and Thompson G.E. Eds. (Electrochem. Soc., Pennington N.J., 1995) pp. 1-12.

[79] Slade R.C.T., Southern J.C., and Thompson I.M., J. Mater. Chem., 1 (1991) 875-879.

[80] Slade R.C.T., Southern J.C., and Thompson I.M., J. Mater. Chem., 1 (1991) 563-568.

[81] Chen F.R., Davis J.G., and Fripiat J.J., J. Catal., 133 (1992) 263-278.

[82] Kawakami H. and Yoshida S., J. Chem. Soc. Faraday Trans., 2 (1986) 1385-1397.

[83] Störr J., NEXAFS Spectroscopy. Springer Series in Surface Science, 25. R. Gomer Ed. (Springer Verlag, Berlin, 1992).

[84] Lopez S., Dunlop H.M., Benmalek M., Tourillon G.T., Wong M.S. and Sproul W.D., Surf. Interface Anal. Submitted.

[85] Briggs D. and Beamson G., Anal. Chem., 64 (1992) 1729-1736.

[86] Lin X.Y., Creuzet F., and Arribart H., J. Phys. Chem., 97 (1993) 7272-7276. 
[87] Marti A. and Spencer N.D., Langmuir, 11 (1995) 4632.

[88] Frisbie C.D., Rozsnyai L.F., Noy A., Wrighton M.S., and Lieber C.M., Science, 265 (1994) 20712074.

[89] Ade H., Zhang X., Cameron S., Costello C., Kirz J., and Williams S., Science, 258 (1992) $972-$ 975.

[90] Cheynet M.C. and David D., Phil Mag. submitted.

[91] Hansen P.L., Brydson R., McComb D.W., and Richardson I., Microsc. Microanal. Microstruc., 5 (1994) 173-182.

[92] Goldstein J.I. and Williams D.B., Microbeam Anal., 1 (1992) 29-53.

[93] Shen Y.R., Nature, 337 (1989) 519-525.

[94] Huttel Y., Bourdié E., Soukiassian P., Mangat P.S., and Hurych Z., J. Vac. Sci. Technol., A11 (1993) 2186-2192.

[95] Brown G.M., Shimizu K., Kobayashi K., Thompson G.E., and Wood G.C., Corrosion Sci., 33 (1992) 1371-1385.

[96] Affrossman S. and MacDonald S.M., Langmuir, 12 (1996) 2090-2095.

[97] Bournel F., Laffon C., Parent P., and Tourillon G., Surf. Sci., 352-354 (1996) 228-231.

[98] Drabold D.A., Adams J.B., Anderson D.C., and Kieffer J., J. Adhesion, 42 (1993) 55-63.

[99] Agrawal D.C. and Raj R. Acta Metall. 37 (1989) 1265-1270 